\title{
Study of Microstructure, Impact Strength on Manual Metal Arc Welding Of Gray Cast Iron Using Enife-Ci Filler Metal
}

\author{
Ravi Butola ${ }^{1}$, Jitendra Kumar ${ }^{2}$, Vikas Verma ${ }^{3}$, Prakash Mahara ${ }^{4}$ \\ ${ }^{1,2}$ PG Scholar, Mechanical Department, Delhi Technological University, Bawana Road, Delhi-110042, India \\ ${ }^{3}$ Research scholar Department Metallurgical and Material Engg IIT Roorkee -247667, India \\ ${ }^{4}$ Junior Work Manager, Ordnance Factory, Raipur Dehradun 248008, India
}

\begin{abstract}
The effect on the microstructure obtained in the heat-affected zone (HAZ) and the carbide zone in the weld metal properties of Casted grey cast iron plates (grade-GJLEN 1561) are used as base material. The welding was carried out with manual shielded metal arc welding using ENiFe-CI filler metal. The welds were prepared by using the arc welding process and filler Nickel base filler materials are used in welding as electrode, which is ductile in nature $85 \mathrm{ENiFe}-\mathrm{CI}$ is the grade of nickel base filler electrode. For knowing the effect of preheat treatment, the plates were firstly heated to near about $400-450^{\circ} \mathrm{C}$ by the help of gas cutting torch and the post weld heat treatment (PWHT) was limited only for 45 minute at $810^{\circ} \mathrm{C}$. The welds were characterized by micro structural analysis, impact test, and tensile test. The Charpy-impact properties of the weldment specimens improved with the PWHT and were somewhat lower than previously developed data on the wrought material.
\end{abstract}

Keyword: - gray cast iron, impact test, microstructure, post weld heat treatment (PWHT), tensile test.

\section{INTRODUCTION}

Weld ability of cast iron has been found to be very poor due to the heterogeneity of matrix phase and non-wet ability of the graphite phase. These phases undergo a series of microstructure changes in the HAZ during weld repairing by fusion welding the project discusses the nature of these changes occurring in the vicinity of the weld zone as well as method of controlling these to get satisfactory weldment. It further discusses the practical aspect of weld joint preparation, the selection of welding process and procedure, the choice of filler metal-composition etc. and degree of pre as well as post weld heat-treatment to obtain defect and stress free welding. The welding of ductile cast iron is not normally practiced in the foundry industry for the reclamation or fabrication of castings, due to the inconsistency of the mechanical and physical properties achieved. Grey irons contain higher amounts of carbon compared to steels which diffuses into the austenite during welding, forming hard brittle phases, namely martensite and carbides at the weld interface. These give rise to poor elongation properties and high hardness values. Weldability of ductile cast iron depends on its original matrix, chemical composition mechanical properties and structure of welding process and working condition. The preheating temperature range depends on the hardenability of the iron chemical composition or carbon equivalent, the size and complexity of the weld and the type of filler materials.

\section{LITERATURE SURVEY}

Pascual et al. [1] have studied welding nodular cast iron with oxyacetylene (OAW) and shielded metal arc welding (SMAW) using $98.2 \% \mathrm{Ni}$ and $\mathrm{Fe}-\mathrm{Cr}-\mathrm{Ni}$ alloy filler materials respectively. They have concluded that welding ductile cast iron with or without preheat is possible but preheating almost always increases weld quality and ductility. OAW results very poor weld metal properties whereas SMAW yields an amount of ductility in the weld metal. Furthermore, using Ni electrodes is another factor increasing the ductility which hinders the carbide formation. El-Banna et al. [3] restoration properties of pearlitic cast iron using SMAW with various filler materials as $\mathrm{Ni}, \mathrm{Fe}-\mathrm{Ni}$ alloy, $\mathrm{Ni}-\mathrm{Cu}$ alloy, stainless and ferrite steel is studied. Also subcritical annealing at $677^{\circ} \mathrm{C}$ is applied. Effect of heat input, preheating and filler materials was examined. When using the ferrite filler material, preheating at $300^{\circ} \mathrm{C}$ becomes the best option for narrowing the 20 melt region and $\mathrm{HAZ}$ with discontinuous carbide and bainite. It is seen that PWHT has reduced the maximum hardness values slightly and finally multipass welding lowers the width of melt region and micro hardness of HAZ. Using filler materials with Ni content can overcome carbide formation however; with ferrite filler a continuous carbide network is observed around the fusion line and HAZ yielded a martensitic structure. Pouranvari [4] carried out a study on welding cast iron using SMAW with Ni based electrodes. He also applied PWHT to the welded pieces. Due to possibility of increasing amount and continuity of carbides preheating is not used and formation of cracks was not reported. Material was fully annealed and a nearly uniform hardness profile is achieved. Again nickel based filler is used to prevent ledeburitic carbide formation in the structure of the weld piece but due to dilution very high carbon contents are come across which cannot be compensated with Ni. This excess amount precipitated as 
graphite in fusion zone. Voigt et al. [5] have studied general HAZ structures of ductile cast irons. SMAW with ENi-CI filler material used with about $300^{\circ} \mathrm{C}$ of preheating. Sub-critical annealing and full annealing is applied to the specimens. In as weld specimens carbides are formed surrounding the graphite nodules and in intercellular regions between nodules. It is concluded that this formation cannot be effectively prevented in PMZ. Martensite, observed in HAZ, cannot be overcome if the preheating temperature is sustained for sufficient times after welding. By application of subcritical annealing martensite was decomposed to ferrite and secondary graphite.

\section{EXPERIMENTAL WORKS}

\subsection{Materials used for experiment}

Casted grey cast iron plates (grade-GJLEN 1561) are used as base material, the chemical composition of main constituents are given below in table

\begin{tabular}{|l|c|c|c|c|c|c|}
\hline \multicolumn{1}{|c|}{ Element } & $\mathrm{C}$ & $\mathrm{Si}$ & $\mathrm{P}$ & $\mathrm{S}$ & $\mathrm{Mn}$ & $\mathrm{Cu}$ \\
\hline$\%$ Composition & 3.5 & 1.25 & 0.14 & 0.101 & 0.64 & 0.48 \\
\hline
\end{tabular}

chemical composition is obtained by XPS machine. Nickel base filler materials are used in welding as electrode, which is ductile in nature. The chemical compositions of main constituents are:

\begin{tabular}{|c|r|r|l|l|}
\hline Element & $\mathrm{C}$ & $\mathrm{Ni}$ & $\mathrm{Si}$ & $\mathrm{Fe}$ \\
\hline$\%$ Composition & 1.2 & & $54.0--$ & 44.8 \\
\hline
\end{tabular}

$85 \mathrm{FN}-\mathrm{ENiFe}-\mathrm{CI}$ is the grade of nickel base filler electrode, these electrodes have high machineability. In experimental work, process involved during the fabrication of defect free test specimen like casting, cutting and welding etc. are discussed.

\section{WELDING OF PLATES}

Providing the plate appropriate fixturing before welding so, that bending of the weld can be avoided which occurs due to sudden contraction weldment. Bending of plates after welding should be avoided. For knowing the effect of preheat treatment, the plates were firstly heated to near about $400-450^{\circ} \mathrm{C}$ by the help of gas cutting torch. Providing flame on the welding surface for a duration of time so that such a temperature range can be obtained. The preheat temperature was measured with the help of thermocouple (range $1000-1200^{\circ} \mathrm{C}$ ) by touching the thermocouple wire to the welding surface. After flame heating of the plate, the temperature was measured with the help of thermocouple wire. If the temperature is below the required, then again flame heating is done so that required temperature will obtained. Soon after, welding was done on the plate with proper alignment of electrode. For normal welding no pre heating is done and the welding is performed at the atmospheric temperature $\left(26^{\circ} \mathrm{C}\right)$.

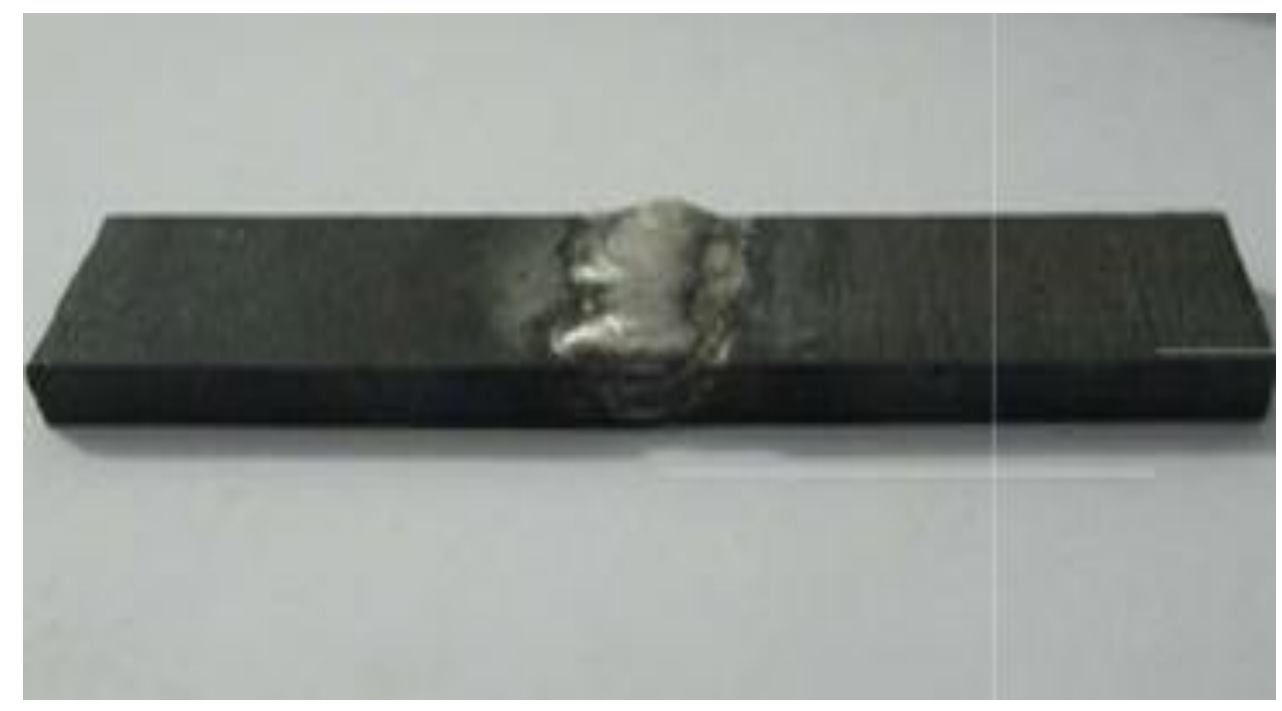

Figure: 1 Welded plate 


\section{PREPARATION OF TEST SPECIMENS VARIOUS TEST SPECIMENS}

1. Tensile test specimen

2. Charpy test specimen

3. Microstructure test specimen

\subsection{Tensile test specimen}

For making the tensile test specimen from welding plates, plates were cut with the help of hand saw, of $25 \mathrm{~mm}$ width and $105 \mathrm{~mm}$ length in the fitting shop. For reducing the thickness of whole welded plates the plate were cut on machine through its surface so that reinforce material of weld get remove. Removing the excess material with the help of grinding machine and hand grinder. For giving the exact shape of tensile test specimen exact drawing was made on plate then, by the help of hand saw cutting was done. Filing was the last job done to get desired dimension only two samples were made one for normal weld and one for preheated.

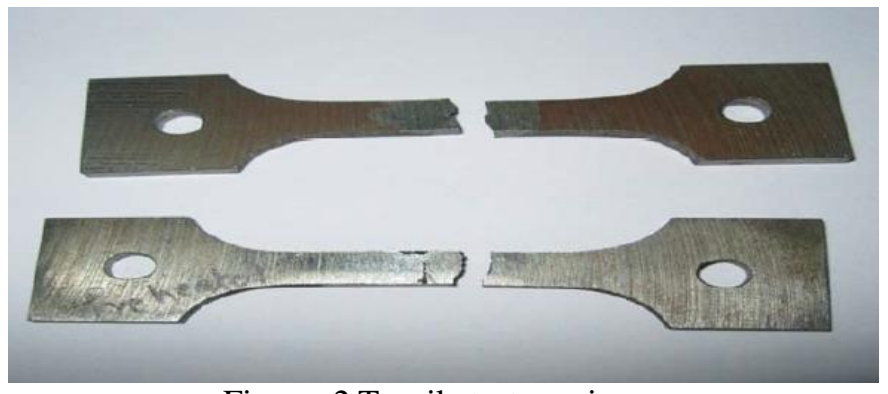

Figure: 2.Tensile test specimen

\subsection{Charpy impact test}

To obtain a more accurate impact strength, (i) the loss due to the positioning needle and (ii)the loss due to air resistance and friction due to machine bearings as factors comprising the loss due to the test machine $\left(\sum L\right)$ were excluded from the absorbed energy. The specific method used to determine factor (ii) was as follows.
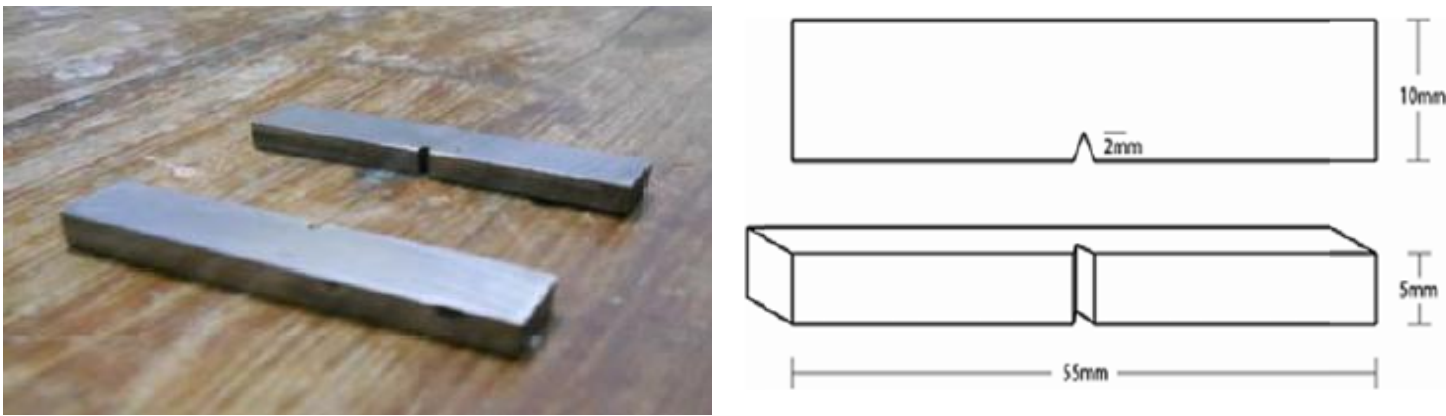

Figure 3: Specimens for impact test and dimension of specimen.

Without any impact test piece being loaded on the test machine, the pendulum was raised to the prescribed angle of elevation $(\alpha)$ and allowed to swing idly. The angle of upward swing $(\beta)$ was then measured and the energy loss calculated. The energy $U$ required to rupture the specimen may be directly read on the graduated scale of machine dial, or may be calculated using relation

$\mathrm{U}=\mathrm{Ui}-\mathrm{Uf}=\mathrm{WR}(\cos \beta-\cos \alpha)$.

This rapture energy or fracture energy is a measure of toughness of the material

\section{Notch impact strength}

The notch impact strength Is is how determine from the following relation Is=U/A

Where $A_{e}$ is effective cross-sectional area of the specimen below the notch before test

\section{Modulus of rapture}

Once the rapture energy $U$ is known the modulus of rapture is obtain from $U r=U / V$

Where $\mathrm{V}_{\mathrm{e}}$ is the effective volume of specimen.

Result obtain after test for simple test specimen

1. Rapture energy $=26$ Jor $2.651 \mathrm{kgf}-\mathrm{m}$

2. Modulus of rapture $=12.05 \times 10^{5} \mathrm{kgf} / \mathrm{m}^{2}$

3. Notch impact strength $=6.6 \times 10^{5} \mathrm{kgf} / \mathrm{m}^{2}$

Result obtain after test from preheated test specimen 
1. Rapture energy $=30 \mathrm{~J} 3.0591 \mathrm{kgf}-\mathrm{m}$

2. Modulus of rapture $=13.5 \times 10^{15} \mathrm{kgf} / \mathrm{m}^{2}$

3. Notch impact strength $=7.6 \times 10^{4} \mathrm{kgf} / \mathrm{m}^{2}$

Result obtain after test from PWHT test specimen

1. Rapture energy $=28 \mathrm{~J} 2.855 \mathrm{kgf}-\mathrm{m}$

2. Modulus of rapture $=12.97 \times 10 \times 5 \mathrm{kgf} / \mathrm{m}^{2}$

3. Notch impact strength $=7.13 \times 10 \times 4 \mathrm{kgf} / \mathrm{m}^{2}$

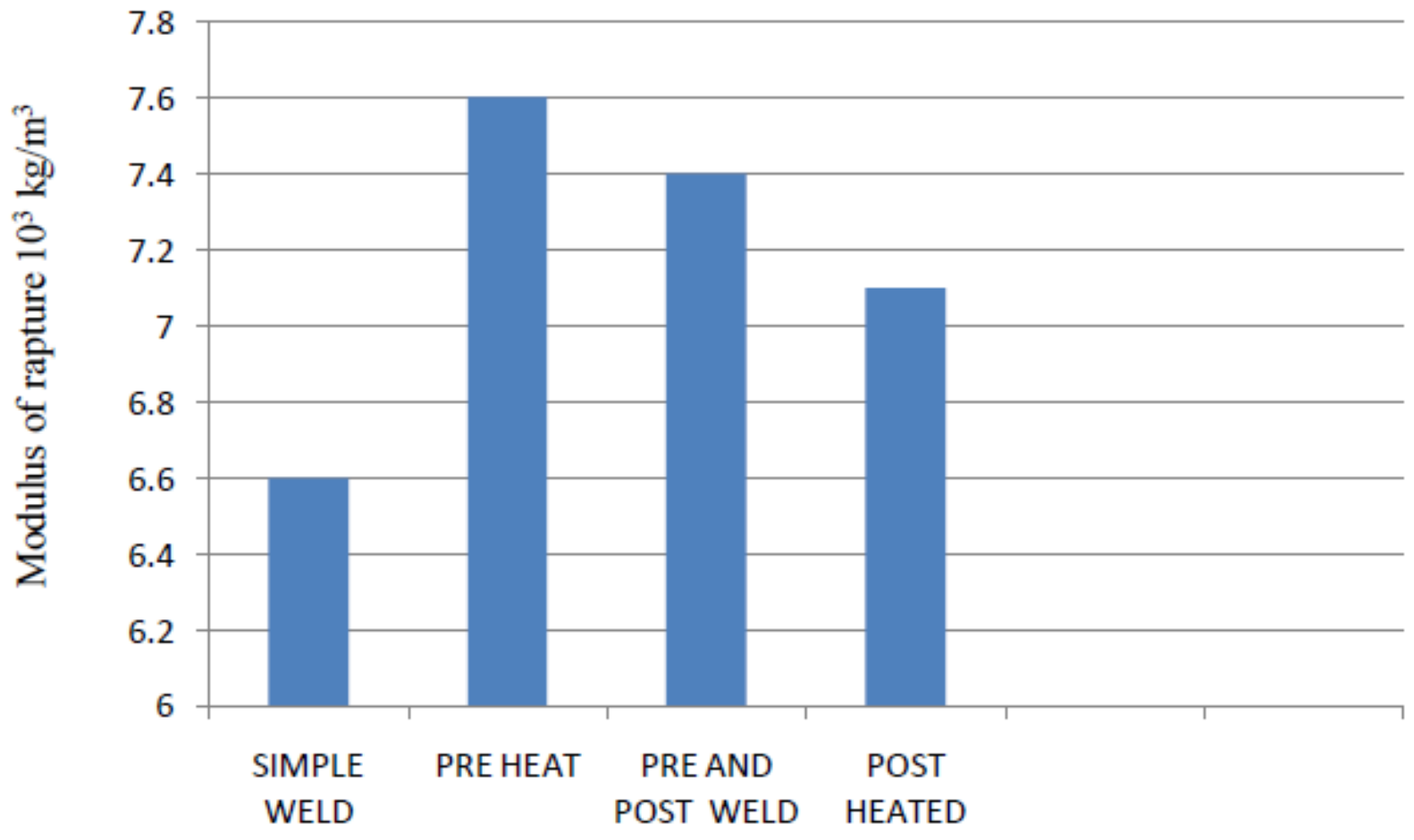

Figure 4: Graph between notch impact strength and various conditions

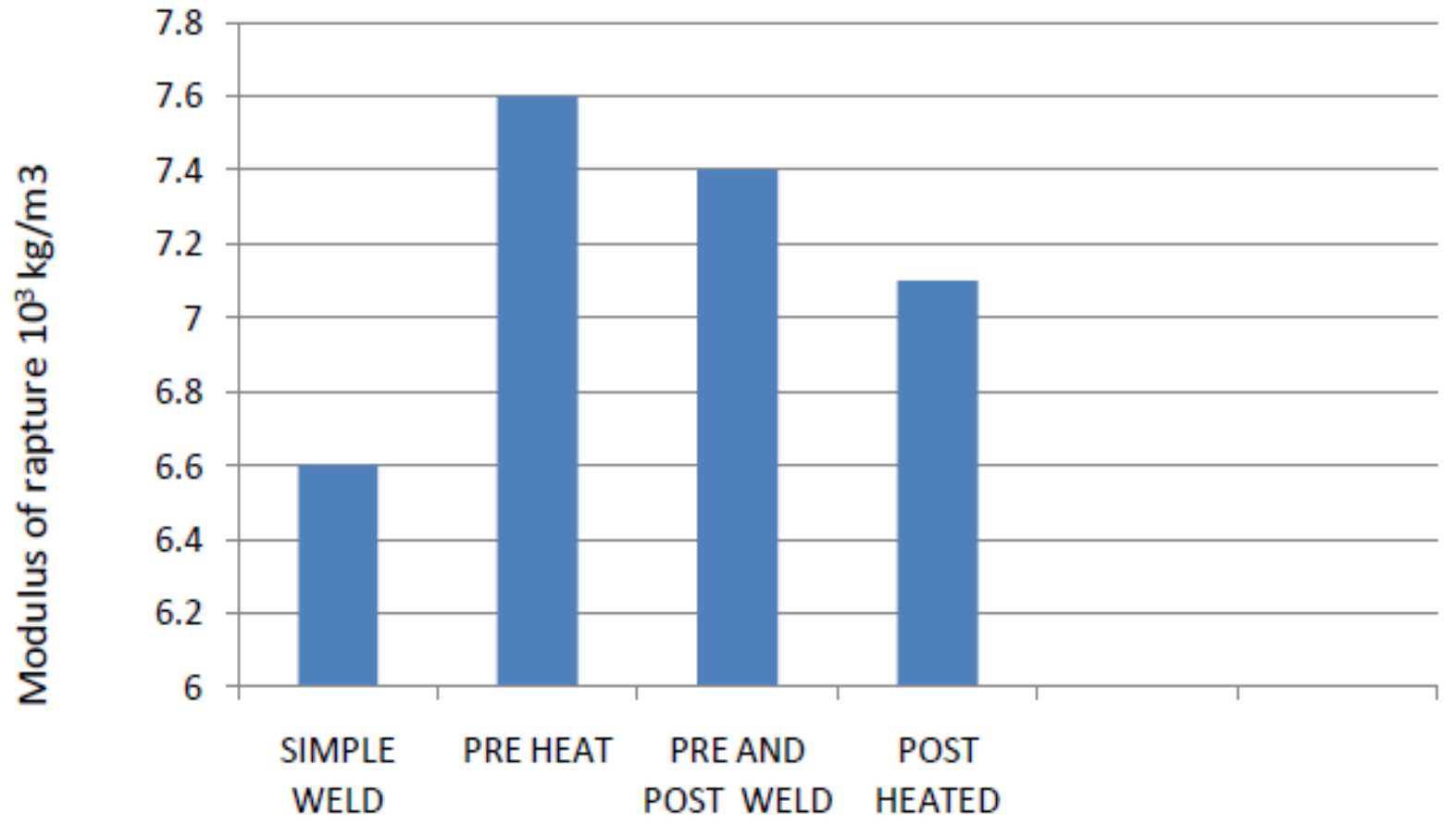

Figure 5: Graph between modulus of rapture and various weld condition 


\subsection{Microstructures}

\section{RESULTS AND DISCUSSION}

Microstructures of different region of welded specimen (base metal, welded zone, heat affected zone and partially melted zone) for different welded condition are given below
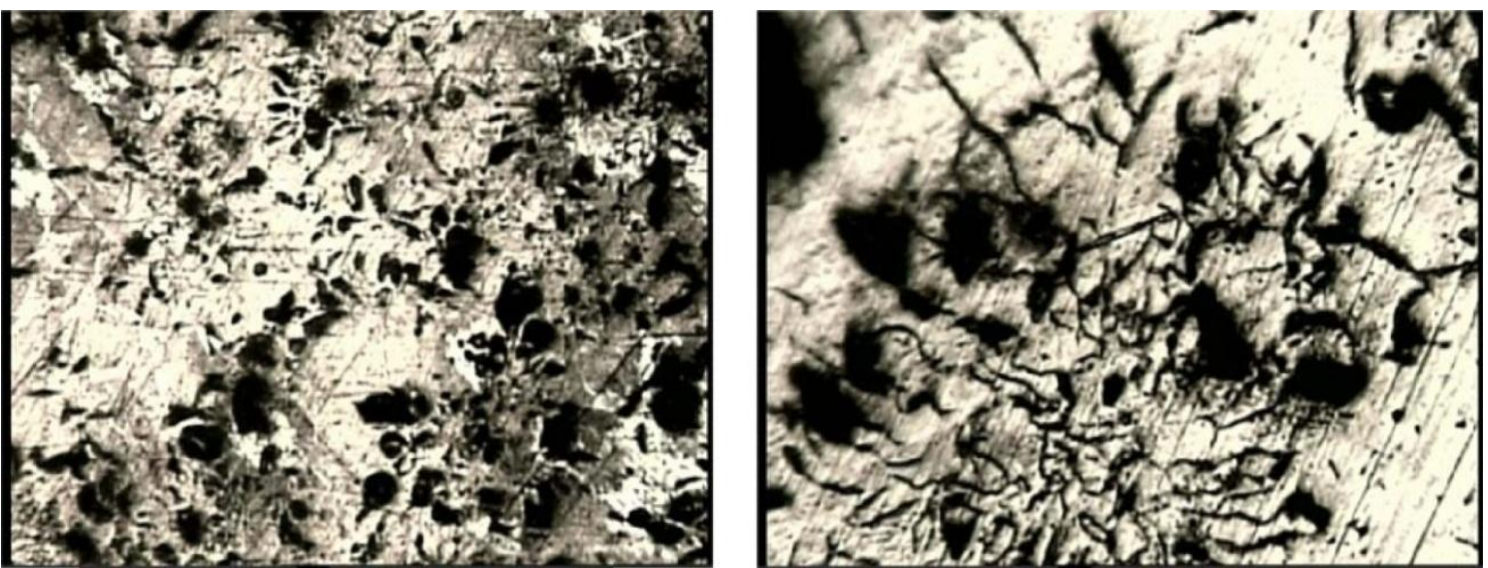

Figure 6.1 (a) Base material (simple weld) 10X, 50X (magnification) microstructure of grey cast iron showing graphite in ferrite matrix and pearlite matrix.
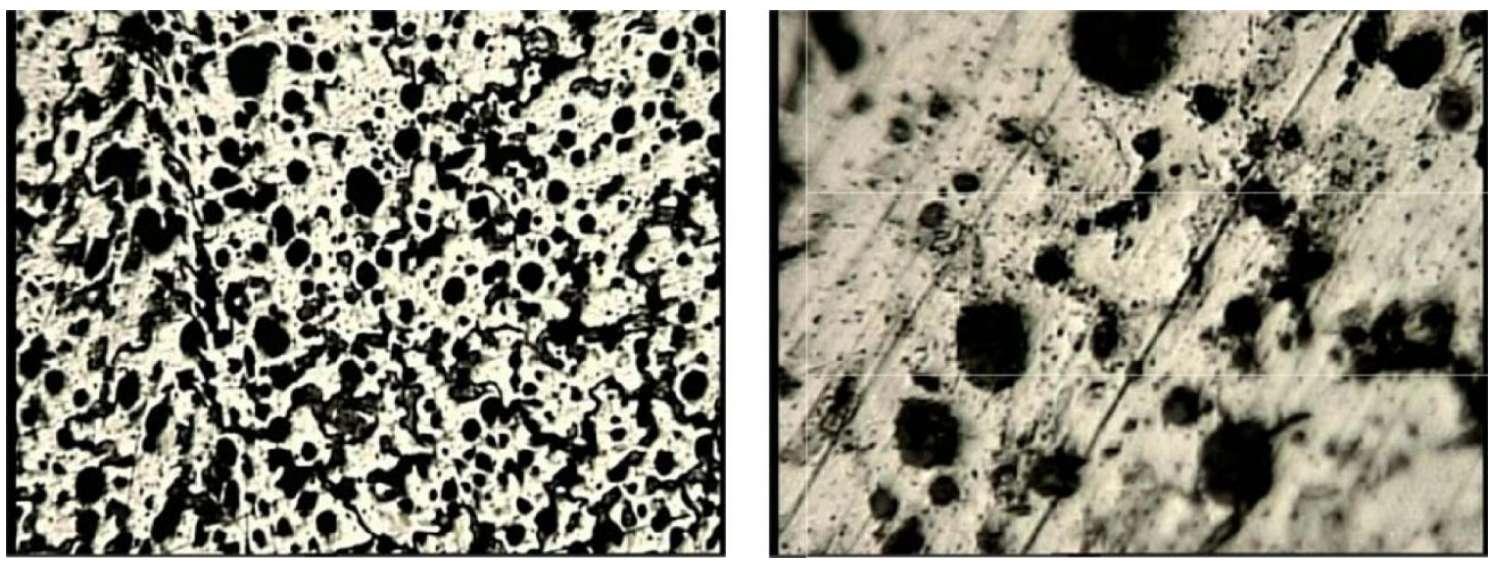

Figure 6.1 (b) welded part (simple weld) 10x, 50x (magnification) welded part showing Graphite in the form of nodules in ferrite matrix and it is ductile nature.
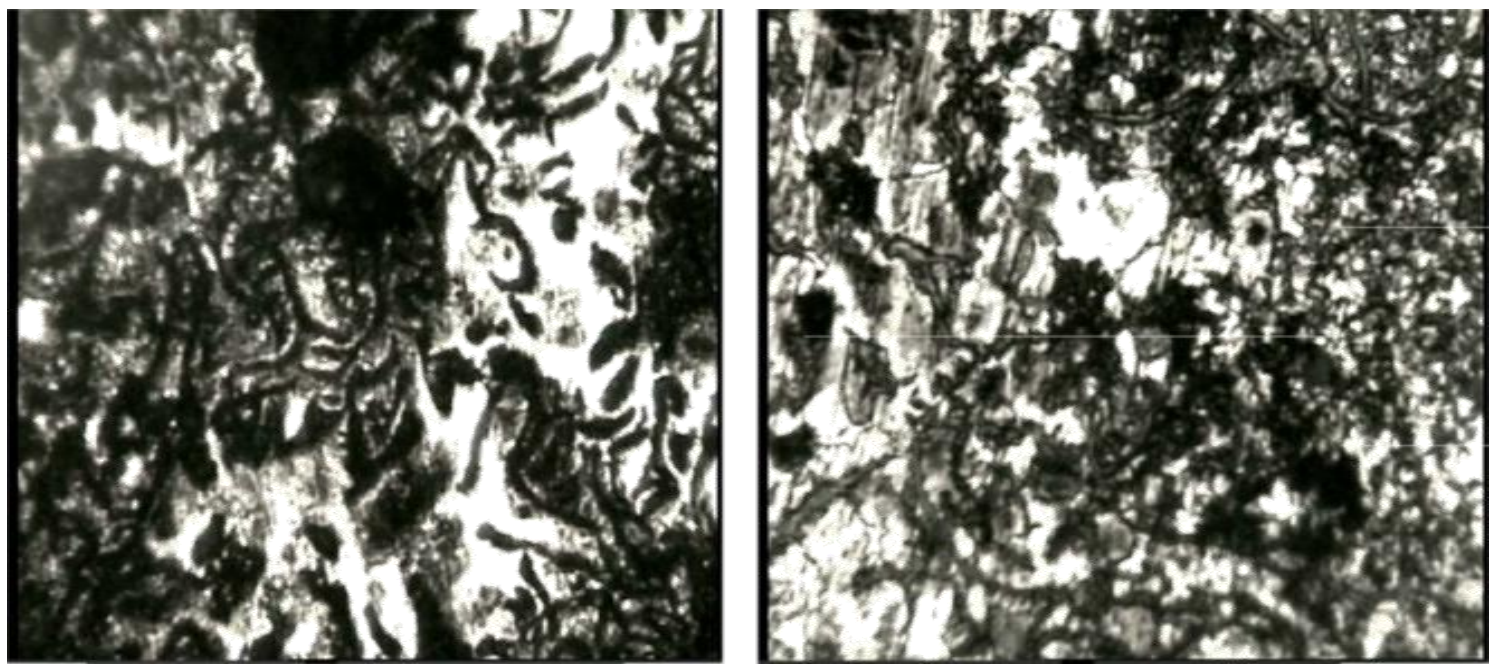

Figure 6.1 (c) Welded and heat affected zone (simple weld) 10X, 50X (magnification) microstructure showing heat affected zone consisting of martensite and fusion part consisting graphite nodules in ferrite matrix. 
VII. CONCLUSIONS

In this study it is observed that formation of martensite and carbide in fusion zone can be controlled via controlling of cooling rate and chemical composition of fusion zone. Result of the current study showed that by using nickel base filler material, the formation of brittle martensite and carbide in fusion zone is prevented. It is of note that, the nickel base filler material has low coefficient of thermal expansion therefore it strains the cast iron HAZ much less than other filler metals, helping in reducing the risk of HAZ cracking. It was shown that HAZ microstructure of grey cast iron contains martensite. Also, PMZ microstructure contains hard eutectic carbide and martensite. To resist against this problem it is advisable to reducing cooling rate via preheating to prevent martensite and carbide formation or post heat treatment to decompose martensite and carbides to softer micro constituents.

\section{REFERENCE}

[1] Pascual M., et al., Analysis of the weldability of ductile iron. Materials Letters, 2008, Vol.62: p. 13591362

[2] El-Banna E. M., Effect of preheat on welding of ductile cast iron. Materials Letters, 1999, vol.41: p. 2026

[3] El-Banna E. M., et al., Study of restoration by welding of pearlitic ductile cast iron. Materials Letters, 2000, vol.42: p. 311-320

[4] Pouranvari M., on the weldability of grey cast iron using nickel based filler metal. Materials and Design, 2010, vol.31: p. 3253-3258

[5] Voigt R. C., et al., A study of heat-affected zone structures in ductile cast iron. Welding Journal, 1983, vol.42: p. $82-88$

[6] Hatate M., et al., Bonding characteristics of spheroidal graphite cast iron and mild steel using electron beam welding process. Vacuum, 2004 vol.73: p. 667-671

[7] Sanghoon K., et al., Cracking behavior in a dissimilar weld between high silicon nodular cast iron and ferritic stainless steel. Metals and Materials International, 2010, vol.16: p. 483-488

[8] Eroğlu M, Aksoy M and Orhan N, Effect of coarse initial grain size on microstructure and mechanical properties of weld metal and HAZ of a low carbon steel, Material Science and Engineering, 1999,vol.259:p 59-66 